Pak. j. sci. ind. res. Ser. A: phys. sci. 2017 60(3) 154-161

\title{
Application of Eco-friendly Antimicrobial Finish Butea monosperma Leaves on Fabric Properties of Polyester and Cotton/Polyester
}

\author{
Shama Sadaf ${ }^{\mathrm{a} *}$, Muhammad Saeed ${ }^{\mathrm{b}}$ and Samia Kalsoom ${ }^{\mathrm{a}}$ \\ ${ }^{a}$ Government College of Home Economics, Gulberg, Lahore, Pakistan \\ ${ }^{b}$ Institute of Education \& Research (IER), University of the Punjab, Lahore, Pakistan
}

(received February 23, 2016; revised September 28, 2017; accepted September 30, 2017)

\begin{abstract}
The study was aimed to check the effect of eco-friendly antimicrobial finish on $100 \%$ polyester and 50/50 cotton/polyester woven fabrics. The leaves' extract of Butea monosperma was used as an ecofriendly antimicrobial finish. The fabric was first desized, scoured, bleached and washed then antimicrobial finish was applied by using pad dry cure method. The aesthetic, comfort and mechanical fabrics properties were checked before and after applying antimicrobial finish. Under aesthetic property stiffness and smoothness appearance was checked, under comfort related property absorbency and air permeability was checked and under mechanical property tear and tensile strength was checked. The antimicrobial finish was checked by using ASTEM E2149 Shake Flask method. The AATCC and ISO standard testing methods were used for checking fabric properties. One way ANOVA statistical test was applied for analysis of results. Antimicrobial finish has increased aesthetic (stiffness, smoothness appearance), comfort (absorbency, air permeability) and mechanical (tensile and tear strengths) properties of polyester and cotton/polyester fabrics. The antimicrobial finish was effective on both $100 \%$ polyester and 50/50 cotton/polyester fabrics up to 25 washes. This study is beneficial to medical industry, paramedical staff, sports wears, home furnishing as well as common people.
\end{abstract}

Keywords: antimicrobial finish, Butea monosperma, polyester, cotton, polyester

\section{Introduction}

For long period of time it has been known that fabrics provide perfect environment for microorganisms development and reproduction. Microorganisms development on fabric is seen during use as well as during storage, so this growth causes health issues to consumers (Sathianarayanan et al., 2010), as well as damage to the physical and mechanical performance of the fabrics. The adverse changes include discoloration, bad odour, mould formation, allergies, detrimental infection, fabric degradation and other related problems (Simonic and Tomsic, 2010).

Therefore, it is very essential to finish all apparels by antimicrobial action to check the bacterial development on fabrics without abolishing desirable features of fabrics. These antimicrobial treated fabrics are used in medicinal garments, carpets, napkins, sanitary, socks and disposable wipers etc. A variety of synthetic antibacterial agents have been used on fabric such as phenols, organo silicones, organometallics and quaternary ammonium salts. These are more intricate and producing

*Author for correspondence; E-mail: sadaf.shama@gmail.com ecological contamination (Joshi et al., 2009). There is need of this type of fabrics in defensive clothes used in hospitals, schools, nursing homes, guesthouses and jampacked public areas. There is a vital market requirement to apply antimicrobial finish to avoid bad smell in intimate apparel, underclothing, socks and sporty wear (Periolatto et al., 2012).

Natural and synthetic fabrics differ significantly in reactions to bacterial development. They equally perform as ready substrates; however, the appliance in the two circumstances is diverse. Fibres which are obtained from natural sources are responsible for bacterial attack for the reason that they absorb water molecules eagerly, and bacterial enzymes can eagerly breakdown their polymer bonds. In natural fibre category cotton, wool and jute are described to be greatest subject to microorganism attack as well as silk and flax. If on $0.5 \mathrm{~g}$ cotton 105 colonies (in $1 \mathrm{~mL}$ water) are pragmatic then logarithmic progression is detected after a few hours. The inhabitants rise from 105 to 109 clusters (Hong et al., 2012). The development of microorganisms is sluggish on synthetic fabrics in contrast to natural 
fabrics. The reason is that on synthetic fabrics microorganisms does not hold much water in their polymer backbone. Though, these fabrics support the holding of moisture in spaces, where these microorganisms reproduce quickly. For instance, foot infection is more noticeable in synthetic fabric socks as compared to socks made from natural fabrics. Hence, for comparison and to gain a good knowledge about microorganism presence on different fabrics, natural, synthetic and blend fabrics was used in current study (Olderman, 1997; Payne and Kudner, 1996).

Due to superior life and health point of view the antimicrobial finished has received tremendous importance in industry as well as in education research. Microbes that are present on fabric are responsible for damaging colour, causing bad odor, illness as well as destruction of fabric. Antimicrobial finish can be applied on sports clothing, towels, undergarments, medical clothing, shoes and upholstery etc. (Varesano et al., 2011). Currently, due to growing awareness of ecofriendly issues and also contamination formed by the use of synthetic dyes, there is increasing interest in dyeing of fabrics using natural dyes. Due to the reason of its improved biodegradability and greater compatibility with the atmosphere, eco-friendly antimicrobial finish lead to relatively little poisonous and allergic responses. From ancient time the remedial power of specific plant resources have been used successfully. According to one estimation there are about 250,000500,000 kinds of such plants in the world. There are also plants which have antimicrobial property (Ali and El-Mohamedy, 2011).

The new procedure were used such as chitosan action (Dev et al., 2009), plasma action (Ghoranneviss et al., 2011; Chena and Chang, 2007), cationization (Hong et al., 2012), enzymatic action (Raja, 2011), microencapsulation and cross-linking (Sathianarayanan et al., 2010) procedures for improvement in antibacterial action by dying fabric with herbal agents. These advanced procedures proved of vast help in enhancement of bioactive properties of final goods. Mahesh et al. (2011) applied pomegranate, neem and turmeric on fabric which resulted in $42 \%, 38 \%$ and $29 \%$ resistance against E. coli and B. cereus. In another study, chitosan and chitosan/PEG were applied on fabrics that showed resistance to $S$. aureus. The effect of the finish lasted up to 5 washes (Bonin, 2008).
In traditional drugs, there are several herbal medicines that have the ability to treat several illness and sicknesses, one of them is Butea monosperma, generally known as 'dhak' or 'palas', 'Flame of forest'. It has several medicinal characteristics and in certain communities gum of $B$. monosperma is used to treat bacteriological and fungal contaminations.

In order to develop a better understanding of the phenomenon, the current study was conducted to assess the antimicrobial properties of leaves of $B$. monosperma by agar diffusion method and fabric properties were checked before and after applying antimicrobial finish (Malpani et al., 2012).

\section{Materials and Methods}

In this study eco-friendly antimicrobial finish was extracted from leaves of Butea monosperma and applied on $100 \%$ polyester and 50/50 cotton/polyester blend. Microorganism's presence was studied on fabrics before and after applying antimicrobial finish. To study the effect of finish on fabrics comfort, mechanical and aesthetic properties were checked. The polyurethane binder was used to improve durability in home laundry. This binder was taken from CHT. The microorganism's presences was checked up to 25 washes in comparisons of control group.

The fabrics samples were cut then treated with antimicrobial finish and tested to govern their effectiveness as antimicrobial fabrics. Extractions of antimicrobial agents from plant were carried out in laboratory of Botany Department of Government College University, Lahore, Pakistan. Antimicrobial finish was applied in National Textile University Faisalabad (NTU). Antimicrobial testing was carried out in Centre of Excellence in Microbiology (CEMB). The fabrics properties were checked in NTU. To check the effect of the antimicrobial finish of $100 \%$ polyester and $50 / 50$ cotton/polyester, first fabrics properties of untreated samples were tested then antimicrobial finish was applied. Again same fabric properties were checked to see whether the properties after applying finish remain same, increase or deteriorate.

Fabric sample. Samples of fabrics $100 \%$ polyester and $50 / 50$ cotton/polyester were purchased from fabric trader of Faisalabad. After purchasing the fabric it was approved by Dean of Faculty of Textiles Engineering $\&$ Technology of Faisalabad. Sample size was 5 yards depending upon, checking fabric properties and tests. The specification of fabrics is given in Table 1. 
Table 1. Fabric specification

\begin{tabular}{|c|c|c|c|c|c|c|}
\hline \multirow[t]{2}{*}{ Name } & \multirow[b]{2}{*}{ Supplier } & \multirow[b]{2}{*}{ Fibre content } & \multicolumn{4}{|c|}{ Properties } \\
\hline & & & Fabric construction & Weight & Warp & Weft \\
\hline $100 \%$ polyester & Faisalabad & $100 \%$ polyester & Twill weave & $\begin{array}{l}0.82 \mathrm{~g} \\
82 \mathrm{Gsm}\end{array}$ & 58 & 58 \\
\hline $50 / 50$ cotton/polyester & Faisalabad & $50 / 50$ cotton/polyester & Plain weave & $\begin{array}{l}2.17 \mathrm{~g} \\
217 \mathrm{Gsm}\end{array}$ & 70 & 55 \\
\hline
\end{tabular}

Unfinished fabric was taken and after purchasing it was processed in NTU. The cotton/polyester 50/50 fabric was desized by using enzyme Bactasal HTN was used in ratio of $1 \mathrm{~g} / \mathrm{L}$. $\mathrm{pH}$ was 5-6 and temperature was 60$70{ }^{\circ} \mathrm{C}$, fabric was dipped for $45 \mathrm{~min}$ in this solution. After desizing the fabric scouring was done by using $\mathrm{NaOH} 4 \mathrm{~g} / \mathrm{L}$ and wetting agent $2 \mathrm{~g} / \mathrm{L}$, detergent was used in the ratio of $1 \mathrm{~g} / \mathrm{L}, 90^{\circ} \mathrm{C}$ temperature was maintained during the process. The cotton/polyester fabric was dipped for $1 \mathrm{~h}$ in bleaching agents which consisted $\mathrm{H}_{2} \mathrm{O}_{2}$ $5 \mathrm{~g} / \mathrm{L}, \mathrm{NaOH}(\mathrm{pH} 10-10.5) 2 \mathrm{~g} / \mathrm{L}$, stabilizer $2 \mathrm{~g} / \mathrm{L}$ and sequesting agent $2 \mathrm{~g} / \mathrm{L}$. The temperature of the process was $90{ }^{\circ} \mathrm{C}$. The fabric was dipped in this solution for one hour. In washing of polyester fabric $4 \mathrm{~g} / \mathrm{L}$ detergent was used. The temperature of bleaching process was $90{ }^{\circ} \mathrm{C}$. The polyester fabric was dipped in washing solution for one hour.

Plants leaves extraction. The leaves of $B$. monosperma were collected in March 2014 from botanical garden of Government College University, Lahore, Pakistan. It was identified and authenticated by Botany Department of Government College University, Lahore. The leaves were washed and shadow dried for two months. After that it was grinded by using a stainless-steel grinder into very fine powder. In Laminar Air Flow Hood poured leaves powder and distilled water (autoclave at 110 degree) in ratio of $100 \mathrm{~g}$ grinded leaves powder and $250 \mathrm{~mL}$ distilled water. This soaked material was left for 7 days and stirred it twice a day. After that it was filtered by use of muslin cloth then filtered again by using Whatman filter paper. The filtered extract of B. monosperma was concentrated by using rotary film evaporator.

Development and application of antimicrobial finish. The antimicrobial finish of $B$. monosperma was prepared in ratio of $200 \mathrm{~mL}$ leaves extract, $50 \mathrm{~mL}$ poly urethane binder and $150 \mathrm{~mL}$ distilled water. The fabric sample was cut which consisted on three meter in length and one foot width from both fabrics, respectively. Labelled it as "un" for untreated and "B" for treated B. monosperma. On untreated polyester and cotton/polyester samples no finish was applied while on treated samples B. monosperma finish was applied. The untreated sample was the control group and the samples treated with $B$. monosperma leaves extract antimicrobial finish were experimental group. The antimicrobial finish was applied by using the pad dry machine, drying was done at $120^{\circ} \mathrm{C}$ for $2 \mathrm{~min}$ and curing was done $150^{\circ} \mathrm{C}$ for $3 \mathrm{~min}$.

After applying antimicrobial finish, microorganisms presence was checked in CEMB by using ASTEM E2 149 shake flask method. The fabric properties i.e., comfort related (absorbency, air permeability), mechanical (tensile strength, tear strength) and aesthetic (stiffness, smooth appearance) properties were checked on all treated and untreated fabrics and sustainability of antimicrobial finish to home laundry was checked by five washes interval.

In aesthetic property for stiffness test, Shirley stiffness tester was used. The surface appearance was checked by using AATCC Technical Manual 2004 TM 124-2001 203 test method. In comfort related properties absorbency was measured by using AATCC test method 79-2000. The absorbency was measured in seconds. The air permeability as comfort related property was measured by using D737-04 standard test methods. The tear strength was measured by using D1424-07 standard test methods. The tensile strength was measured by using the European Standard EN ISO 13934-1:1999 has the status of a British Standard ICS 59.080.30. Tests on all samples were carried out in a standard atmosphere having a relative humidity of $65 \pm 2 \%$ at $21 \pm 1{ }^{\circ} \mathrm{C}$ (70 $\left.\pm 2{ }^{\circ} \mathrm{F}\right)$. There should be no oil, water and grease on the samples when experiment was conducted. 


\section{Results and Discussion}

The antimicrobial finish was studied in comparison on control group (untreated fabric) and experimental group (treated fabric). The SEM test was also performed to check the presence of antimicrobial finish on fabrics.

The figure showed the SEM micrographs of untreated and treated polyester fabric with eco-friendly antimicrobial finish of leaves of $B$. monosperma. The application of $B$. monosperma antimicrobial finish is observed clearly on polyester and cotton/polyester fabric.

Effect of antimicrobial finish on aesthetic property of polyester and cotton/polyester fabric. The aesthetic property of polyester and cotton/polyester was checked before and after applying antimicrobial finish. Under aesthetic property stiffness and smoothness appearance was checked, results are given in Table 2.

Table 2 shows that $B$. monosperma plant leaves extracts antimicrobial finish have significant effect $(\mathrm{p}=0.000)$ on stiffness (warp and weft) of polyester fabric as compared to control group. A one way ANOVA showed that $(\mathrm{p}=0.016)$ of smoothness appearance is statistically significant because it is below then 0.05 .

In case of cotton/polyester fabric it shows that B. monosperma plant leaves extracts antimicrobial finish have significant effect ( $\mathrm{p}=0.000$ ) on stiffness (warp and weft) of polyester fabric as compared to control group. A one way ANOVA showed that $(\mathrm{p}=0.016)$ of smoothness appearance is statistically significant because it is below than 0.05 . The stiffness and surface appearance of polyester and cotton/polyester fabrics have increased.

Effect of antimicrobial finish on comfort property of polyester fabric. The comfort related property of polyester and cotton/polyester was checked before and after applying antimicrobial finish. Under comfort related property absorbency and air permeability was checked, results are given in Table 3.

Table 2. Effect of antimicrobial finish on properties of polyester and cotton/polyester fabric

\begin{tabular}{|c|c|c|c|c|}
\hline Properties & Samples & Mean difference (I-J) & Standard error & Sig. ${ }^{b}$ \\
\hline \multicolumn{5}{|l|}{ Polyester fabric } \\
\hline Stiffness warp & Control vs $B$. monosperma & $-1.467^{*}$ & 0.269 & 0.001 \\
\hline Stiffness weft & Control vs $B$. monosperma & $-0.200^{*}$ & 0.062 & 0.012 \\
\hline Stiffness (warp+weft) & Control vs $B$. monosperma & $-0.900 *$ & 0.140 & 0.000 \\
\hline Smoothness appearance & Control vs $B$. monosperma & $-0.230^{*}$ & 0.068 & 0.016 \\
\hline \multicolumn{5}{|l|}{ Cotton/polyester fabric } \\
\hline Stiffness warp & Control vs $B$. monosperma & $0-.633^{*}$ & 0.113 & 0.001 \\
\hline Stiffness weft & Control vs $B$. monosperma & $-0.200^{*}$ & 0.062 & 0.012 \\
\hline Stiffness (warp+weft) & Control vs $B$. monosperma & $-0.480^{*}$ & 0.092 & 0.000 \\
\hline Smoothness appearance & Control vs $B$. monosperma & $-0.230^{*}$ & 0.068 & 0.016 \\
\hline
\end{tabular}

Table 3. Effect of antimicrobial finish on comfort related property of polyester and cotton/polyester fabric

\begin{tabular}{|c|c|c|c|c|}
\hline Properties & Samples & Mean difference (I-J) & Standard error & Sig. ${ }^{b}$ \\
\hline \multicolumn{5}{|l|}{ Polyester fabric } \\
\hline Absorbency & Control vs $B$. monosperma & $1.333^{*}$ & 0.471 & 0.022 \\
\hline Air permeability face & Control vs $B$. monosperma & $-43.333^{*}$ & 3.951 & 0.000 \\
\hline Air permeability back & Control vs $B$. monosperma & $-38.000^{*}$ & 5.196 & 0.000 \\
\hline Air permeability (face \& back) & Control vs $B$. monosperma & $-45.300^{*}$ & 5.178 & 0.000 \\
\hline \multicolumn{5}{|l|}{ Cotton/polyester fabrics } \\
\hline Absorbency & Control vs $B$. monosperma & $21.000^{*}$ & 5.802 & 0.007 \\
\hline Air permeability face & Control vs $B$. monosperma & $-8.367^{*}$ & 1.904 & 0.002 \\
\hline Air permeability back & Control vs $B$. monosperma & -4.100 & 1.782 & 0.050 \\
\hline Air permeability (face \& back) & Control vs $B$. monosperma & $-7.460^{*}$ & 3.152 & 0.031 \\
\hline
\end{tabular}


Table 3 shows that $B$. monosperma plant leaves extracts antimicrobial finish have significant effect $(\mathrm{p}=0.022)$ on absorbency of polyester fabric as compared to control group. A one way ANOVA showed that $(\mathrm{p}=0.000)$ of air permeability (face and back) is statistically significant because it is below than 0.05 .

In case of cotton/polyester fabric result shows that B. monosperma plant leaves extracts antimicrobial finish have significant effect $(\mathrm{p}=0.007)$ on absorbency of cotton/polyester fabric as compared to control group. A one way ANOVA showed that $(p=0.031)$ of air permeability (face and back) is statistically significant because it is below than 0.05 . The absorbency and air permeability have increased of both fabrics.

Effect of antimicrobial finish on mechanical property of polyester fabric. The mechanical property of polyester and cotton/polyester was checked before and after applying antimicrobial finish. Under mechanical property tear and tensile strength was checked and the results are given in Table 4.

Table 4 shows that $B$. monosperma plant leaves extracts antimicrobial finish have significant effect $(\mathrm{p}=0.042)$ on tensile strength (warp + weft) of polyester fabric as compared to control group. A one way ANOVA showed that $(\mathrm{p}=0.000)$ of tear strength (warp+weft) is statistically significant because it is below than 0.05 .

In case of cotton/polyester fabric result shows that B. monosperma plant leaves extracts antimicrobial finish have significant effect $(\mathrm{p}=0.034)$ on tensile strength (warp+weft) of cotton/polyester fabric as compared to control group. A one way ANOVA showed that $(p=0.000)$ of tear strength (warp+weft) is statistically significant because it is below then 0.05 . The tear and tensile strength of both fabrics have increased. In one study the antimicrobial finish was applied by use of chitosan and chitosan PEG on cotton fabric and result revealed that it increased the tensile strength. This study support the present study (Bonin, 2008). In another study Sericin was applied on cotton fabric by pad dry cure method. The tensile strength is increased by this treatment. This study support the current study (Doakhan et al., 2013).

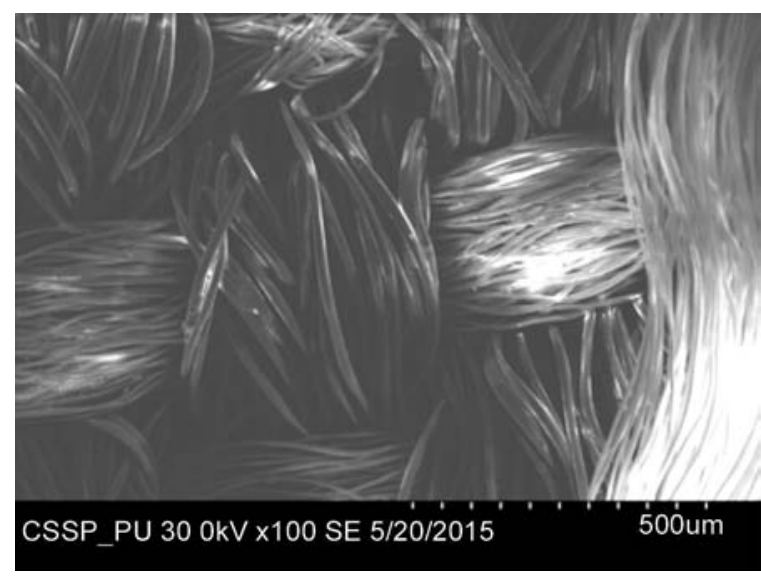

Fig. 1. SEM micrograph of untreated polyester fabric.

Table 4. Effect of antimicrobial finish on mechanical property of polyester and cotton/polyester fabrics

\begin{tabular}{|c|c|c|c|c|}
\hline Properties & Samples & Mean difference (I-J) & Std. error & Sig. ${ }^{b}$ \\
\hline \multicolumn{5}{|l|}{ Polyester fabric } \\
\hline Tensile strength warp & Control vs $B$. monosperma & $-139.034^{*}$ & 42.146 & 0.011 \\
\hline Tensile strength weft & Control vs $B$. monosperma & -32.877 & 27.482 & 0.266 \\
\hline Tensile strength (warp + weft) & Control vs $B$. monosperma & -68.191 & 35.331 & 0.042 \\
\hline Tear strength warp & Control vs $B$. monosperma & $-1646.667^{*}$ & 163.095 & 0.000 \\
\hline Tear strength weft & Control vs $B$. monosperma & -1654.617 & 160.213 & 0.000 \\
\hline Tear strength (warp + weft) & Control vs $B$. monosperma & $-1558.000^{*}$ & 126.720 & 0.000 \\
\hline \multicolumn{5}{|l|}{ Cotton/polyester fabric } \\
\hline Tensile strength warp & Control vs $B$. monosperma & 130.106 & 58.482 & 0.042 \\
\hline Tensile strength weft & Control vs $B$. monosperma & 125.206 & 55.518 & 0.054 \\
\hline Tensile strength (warp + weft) & Control vs $B$. monosperma & 13.681 & 92.422 & 0.034 \\
\hline Tear strength warp & Control vs $B$. monosperma & $413.333^{*}$ & 131.656 & 0.014 \\
\hline Tear strength weft & Control vs $B$. monosperma & $1020.000^{*}$ & 154.704 & 0.000 \\
\hline Tear strength (warp + weft) & Control vs $B$. monosperma & $766.000^{*}$ & 125.618 & 0.000 \\
\hline
\end{tabular}


Microorganisms testing after fabric washes. A summary of microorganisms testing after five washes interval is given in Table 5 .

Table 5. Quantitative analysis test results of treated and untreated polyester sample

\begin{tabular}{llllll}
\hline \hline \multirow{2}{*}{ Washes } & \multicolumn{2}{c}{ Polyester } & & \multicolumn{2}{c}{ Cotton/Polyester 50/50 } \\
\cline { 2 - 3 } \cline { 5 - 6 } & Untreated & B. monosperma & & Untreated & B. monosperma \\
\hline 0 & 1 & 0 & 1 & 0 \\
5 & 0 & 0 & 0 & 0 \\
10 & 0 & 0 & 1 & 0 \\
15 & 0 & 0 & 0 & 0 \\
20 & 1 & 0 & 0 & 0 \\
25 & 1 & 0 & 0 & 0 \\
\hline \hline
\end{tabular}

On untreated and treated fabrics only those microorganisms were studied which were detected during the experiment. On $100 \%$ polyester, were gram -ve short thin rods, coccus, coccus bacilli and gram +ve cocci cluster were observed. On untreated cotton/polyester fabric gram -ve coccus and fungus were observed. The reason was that antimicrobial finish was effective against microorganisms. Crosstab statistical technique was used. The polyester and cotton/polyester fabric treated with B. monosperma showed $100 \%$ reduction against after 25 successive washes, while on untreated fabrics microorganisms presences was observed. In another study chitosan and chitosan/PEG antimicrobial finish was applied on cotton fabric. The AATCC standard test method was used for antibacterial testing against Staph. aureus. Results showed that antibacterial samples showed bacterial resistance up to 25 washes, while the samples laundered 50 time revealed no resistance against Staph. aureus. This study support the present study that antimicrobial finish was effective up to 25 washes (Bonin, 2008). The antimicrobial finish was extracted from Aloe vera plant and applies on $100 \%$ cotton fabric by pad dry method. The AATCC agar diffusion method was used to check antimicrobial testing against $S$. aureus. The treated sample exhibited $98 \%$ reduction against Staph. aureus after 50 laundries. This study also support the present study that antimicrobial finish can be affective up to 25 washes as it is effective up to 50 washes. This study reduces $98 \%$ reduction of microbes while present study reduces $89 \%$ reduction in microorganisms (Jothi, 2009). The antimicrobial finish of neem, turmeric and

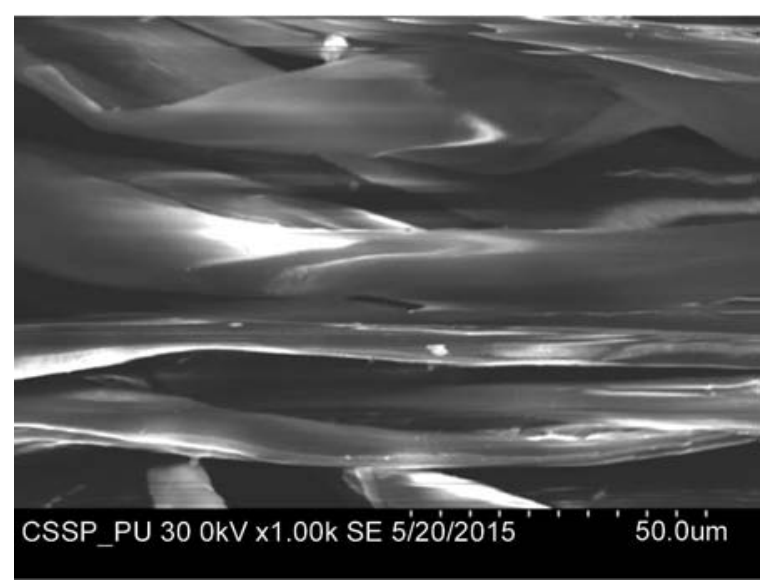

Fig. 2. SEM micrograph of treated polyester fabric.

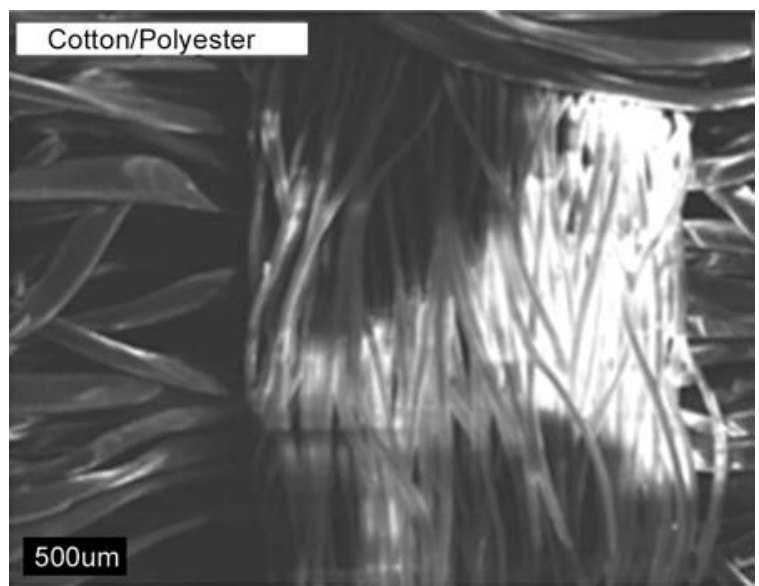

Fig. 3. SEM micrographs of treated cotton-polyester fabric.

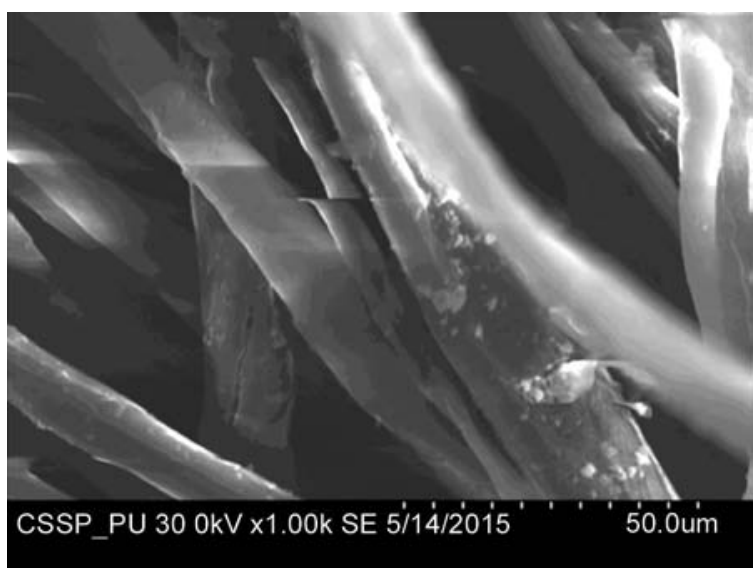

Fig. 4. SEM micrographs of untreated cottonpolyester fabric. 
pomegranat was applied against E. coli and B.cereus. This finish lasts only up to 5 washes. This study somehow also support the present study as it lasts up to 5 washes (Mahesh et al., 2011).

\section{Conclusion}

The Butea monosperma antimicrobial finish was applied on $100 \%$ polyester and 50/50 cotton/polyester fabrics. The SEM results showed the presences of finish on fabrics. Fabrics properties were checked before and after applying antimicrobial finish. In aesthetic property, stiffness was increased and smooth appearances remain same. In comfort related property, absorbency and air permeability was increased. As antimicrobial finish was applied, it pushed apart the molecules of fabric and make it space by forming bond with fabric $\mathrm{OH}$ group. As finish applied in solution form due to which absorbency increased as well as air permeability was also increased. As spaces present for water (absorbency) so these spaces also caused increased absorbency. In mechanical property tear and tensile strength was increased. The presences of microorganisms was checked before and after applying antimicrobial finish up to 25 washes by five washes interval. The ASTM shake flask method was used to check antimicrobial finish. The results showed that B. monosperma showed $100 \%$ reduction against microorganism up to 25 washes.

\section{References}

Ali, N., El-Mohamedy, R. 2011. Eco-friendly and protective natural dye from red prickly pear (Opuntia lasiacantha Pfeiffer) plant. Journal of Saudi Chemical Society, 15: 257-261.

Bonin, L.E. 2008. Durable and Reusable Antimicrobial Textiles, in partial fulfillment of the requirements for the degree of M.Sc. University of Louisiana at Lafayette, USA.

Chena, C., Chang, W.Y. 2007. Antimicrobial activity of cotton fabric pretreated by microwave plasma and dyed with onion skin and onion pulp extractions. Indian Journal of Fibre \& Textile Research, 32: 122-125.

Dev, V.G., Venugopal, J., Sudha, S., Deepika, G., Ramakrishna, S. 2009. Dyeing and antimicrobial characteristics of chitosan treated wool fabrics with henna dye. Carbohydrate Polymers, 75: 646-650.
Doakhan, S., Montazer, M., Rashidi, A., Moniri, R., Moghadam, M. 2013. Influence of sericin $/ \mathrm{TiO}_{2}$ nanocomposite on cotton fabric: Part 1. Enhanced antibacterial effect. Carbohydrate Polymers, 94: 737-748.

Ghoranneviss, M., Shahidi, S., Anvari, A., Motaghi, Z., Wiener, J., Šlamborová, I. 2011. Influence of plasma sputtering treatment on natural dyeing and antibacterial activity of wool fabrics. Progress in Organic Coatings, 70: 388-393.

Hong, K.H., Bae, J.H., Jin, S.R., Yang, J.S. 2012. Preparation and properties of multi-functionalized cotton fabrics treated by extracts of gromwell and gallnut. Cellulose, 19: 507-515.

Joshi, M., Wazed Ali, S., Purwar, R., Rajendran, S. 2009. Ecofriendly antimicrobial finishing of textiles using bioactive agents based on natural products. Indian Journal of Fibre and Textile Research, 34: 295-304.

Jothi, D. 2009. Experimental study on antimicrobial activity of cotton fabric treated with aloe gel extract from Aloe vera plant for controlling the Staphylococcus aureus (bacterium). African Journal of Microbiology Research, 3: 228-232.

Mahesh, S., Manjunatha, A.H., Reddy, V., Kumar, G. 2011. Studies on antimicrobial textile finish using certain plant natural products. In: International Conference on Advances in Biotechnology and Pharmaceutical Sciences (ICABPS'2011) Bangkok, Dec.

Malpani, M., Rajput, P., Mane, V., Deshpande, A. 2012. Phytochemical Screening, Characterization and In Vitro Antimicrobial Activity of Butea monosperma Flower, Leaves and Gum: Methanolic and Aqueous Extract. International Journal of Chemistry Research, 3: $17-20$

Olderman, J. 1997. Surgical nonwovens. Nonwoven Ind, 10: 38-43.

Payne, J., Kudner, D. 1996. A new durable antimicrobial finish for cotton textiles. American dyestuff reporter, 85: 26-30.

Periolattoa, M., Ferreroa, F., Vineisb, C. 2012. Antimicrobial chitosan finish of cotton and silk fabrics by UV-curing with 2-hydroxy-2-methylphenylpropane-1-one. Carbohydrate Polymers, 88: 201 205. 
Raja, R.V., Ramanathan, T., Savitha, S. 2009. Studies on wound healing property of coastal medicinal plants. Journal of Bioscience and Technology, 1: 39-44.

Sathiyanarayanan, M.P., Bhat, N.V., Kokate, S.S., Walnuj, V.E. 2010. Antibacterial finish for cotton fabric from herbal products. Indian Journal of Fibre \& Textile Research, 35: 50-58.
Simonic, B., Tomsic, B. 2010. Structure of novel antimicrobial agents for textiles a review. Textile Research Journal, 80: 65-83.

Varesano, A., Vineis, C., Aluigi, A., Rombaldoni, F. 2011. Antimicrobial polymers for textile products. Science against microbial pathogens. Communicating current research and technological advances, 3: $99-110$. 